\title{
WHEN THE VIRTUAL INFLUENCES REALITY. THE CONSERVATION PROJECT OF THE TOLEDO GATE IN CIUDAD REAL (SPAIN)
}

\author{
A. Almagro Vidal ${ }^{\text {a }}$, I. Ramírez González ${ }^{\text {b }}$ C. Clemente San Román ${ }^{c}$ \\ ${ }^{\text {a }}$ Fundación Montemadrid, Madrid, Spain. ana.almagro@gmail.com \\ ${ }^{\mathrm{b}}$ Escuela de Arquitectura, Universidad Europea de Madrid, Madrid, Spain. ramirez@g3a.es \\ ${ }^{\mathrm{c}}$ Universidad de Alcalá de Henares, Madrid, Spain. arquitecto@ carlosclemente.com
}

Session E4 - Integration, conservation of tangible and intangible cultural heritage

KEY WORDS: Virtual Archaeology, reconstruction hypothesis, 3D model, interpretation, public awareness, restoration project, interdisciplinarity

\begin{abstract}
:
The Toledo Gate of Ciudad Real, Spain, constructed between the late $13^{\text {th }}$ and early $14^{\text {th }}$ centuries, is the last remaining portion of a once complete medieval city wall. It represents the long history of the city and constitutes its main heritage symbol, dividing the historic city centre from the later $19^{\text {th }}$ and $20^{\text {th }}$ century expansions. In October 2012, the Town Hall and the Montemadrid Foundation started the conservation works to preserve this important monument. The preliminary phase of this project included an in-depth series of scientific studies which were carried out by a multidisciplinary team focusing on archival research, historic investigations, archaeological excavations as well as material composition analysis and main treatment application tests. As a result of these studies a series of virtual 3D models were created to inform, discuss and study the monument. A first digital model permitted visualization of the gate in the 19th century and how the main entrance to the city was integrated as a fundamental part of the city walls. This virtual reconstruction also became an important part of the campaign to raise awareness among the citizens towards a monument that had remained in the shadows for the last century, isolated in a roundabout after the systematic demolition of the city walls in the late $19^{\text {th }}$ century.
\end{abstract}

Over the last three years and as a result of these archaeological and historic investigations and subsequent virtual models, surprisingly new and interesting data were brought to light thus permitting the establishment and corroboration of a new and updated hypothesis of the Toledo Gate that goes beyond the previous ideas. As a result of these studies a new architectural typology with construction techniques of has been suggested.

This paper describes how the results of this continuous and interdisciplinary documentation process have benefitted from a computer graphic reconstruction of the gate. It highlights how virtual reconstruction can be a powerful tool for conservation decision making and awareness raising. Furthermore, the interesting results of the final reconstruction hypothesis convinced the technical team responsible for the conservation to alter some aspects of the final project physical interventions in order to focus on some of the features and conclusions discovered through the virtual model study.

\section{INTRODUCTION}

This paper is a complement and a follow up to a previous article published and presented at the CIPA Symposium in Prague in 2011 (Almagro et al, 2011), when the project at the Toledo Gate in Ciudad Real was at a preliminary stage. This update describes in greater detail the documentation, investigations and analysis from multiple points of view in order to define conservation guidelines and criteria for the intervention. During this period of time the conservation works have been carried out and at the same time further historical research and archaeological investigation have been implemented, including the production of several 3D models. Archaeological evidences, historical data and the study of contemporary examples have been combined together in these models from an interdisciplinary perspective.

This rich process has resulted in some interesting and surprising results and conclusions that affected directly the final physical intervention during the restoration project and have increased enormously the historical and constructive knowledge of the original gate and its architectural typology.

\section{THE PROJECT FRAMEWORK}

The Toledo Gate conservation project was an initiative promoted in 2009 by the Montemadrid Foundation (formerly Caja Madrid Foundation) and the Town Hall of Ciudad Real in the autonomous region of Castilla-La Mancha in the south of Spain.

The aim of this project was to conserve and enhance the cultural values of the main historical monument of the city, the Toledo Gate. This important monument ended up isolated and forgotten in a traffic roundabout, completely out of context and affected by serious problems of humidity, heavy traffic pollution and lack of maintenance (Fig.1). 


\subsection{Historical background}

The city of Ciudad Real (Royal City) was founded in the $13^{\text {th }}$ century under royal order by King Alfonso the $10^{\text {th }}$, known as "The Wise". He decreed the construction of the city fortifications, which included 130 towers, 8 gates and almost $4.600 \mathrm{~m}$ of walls. Ciudad Real was originally an unimportant village informally settled at a crossroads (Villegas, 1981: 5681). Historically the urban development of the city never densely populated inside the wall enclosure, leaving extensive areas of cultivated fields inside the walls (Figs. $2 \& 3$ ). This changed in the late $19^{\text {th }}$ century with the dramatic and rapid growth of the city.

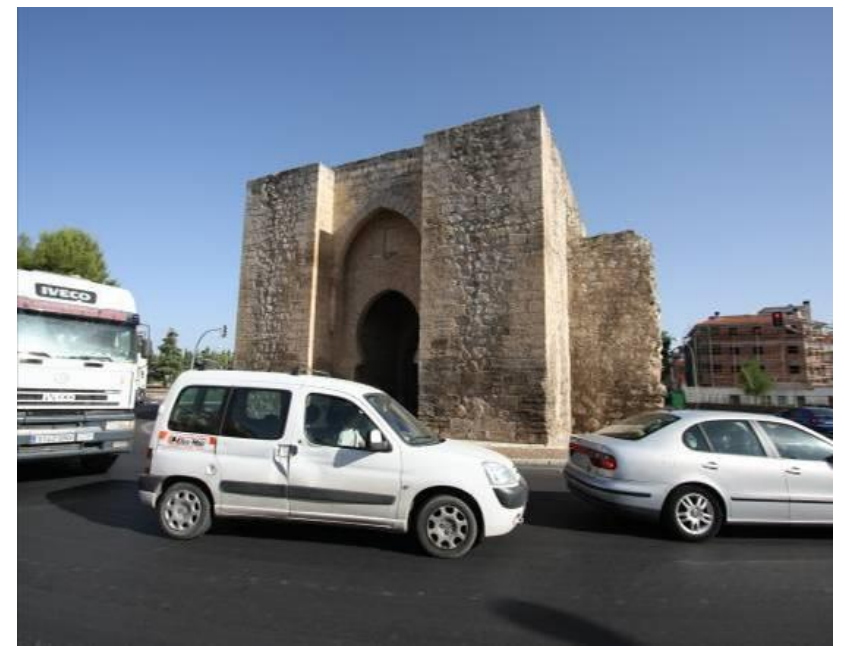

Figure 1. The Toledo Gate as a roundabout before the conservation project

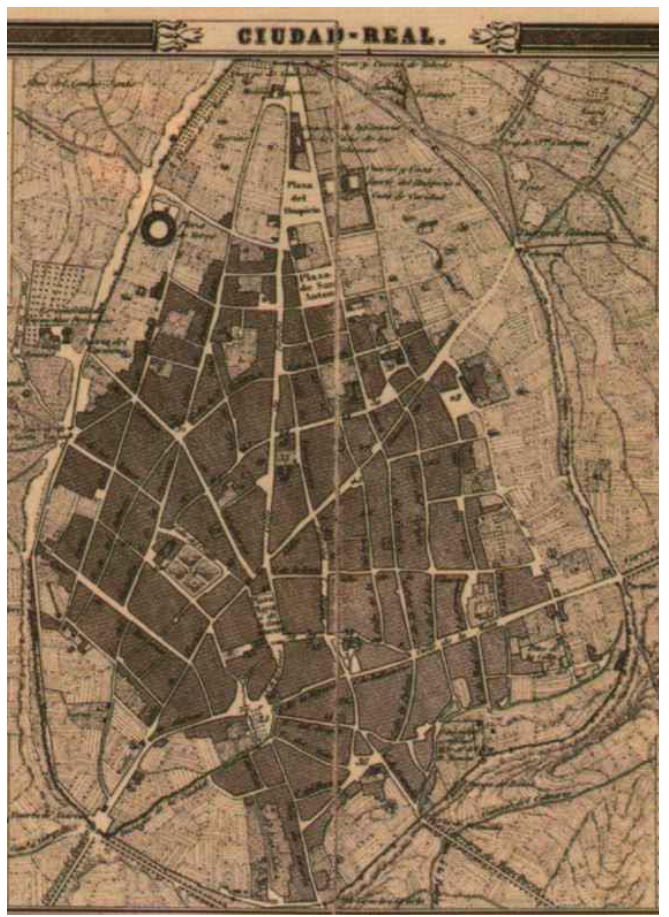

Figure 2. The city of Ciudad Real from the plan of Francisco Coello, in $1860 \mathrm{ca}$.
The urban pressure and the lack of a strong historic identity linked to the walls and its gates enabled the demolition of almost the entire wall enclosure as well as its distributed gates. This permitted the constrained city to expand into the surrounding plain and oxygenate its urban growth.

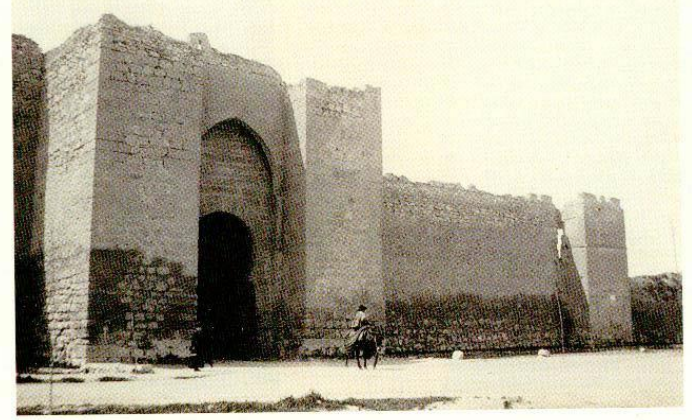

Figure 3. The Toledo Gate and the adjacent walls and tower, at the beginning of the $19^{\text {th }}$ century

During the demolition of the walls and gates the construction materials, especially fine masonry and dressed stone, were reused in the construction of other buildings such as the Casino and the bull ring. The debris from the walls, mainly the rammed earth and rubble, were reused to refill swampy areas to the north of the city.

Only the Toledo Gate has survived together with a small portion of the walls, still visible to the Southeast of the city centre (Fig. 4). However, the urban structure still preserves traces of the enclosure and the original name of the gates can be identified through the names of adjacent streets and plazas.

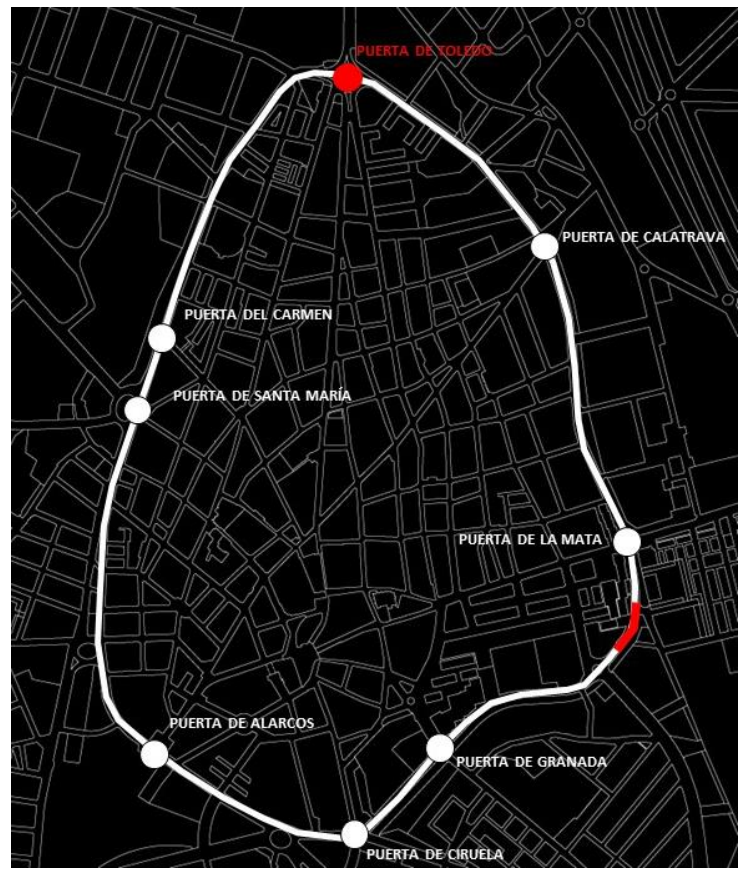

Figure 4. The city walls that surrounded the city centre until the $19^{\text {th }}$ century with the different gates. Highlighted in red, the only remains existing today 


\subsection{The conservation project}

One of the main issues that this conservation project faced, above all, was to recover the spirit of a walled city where the gate and its mechanisms operated as a principle entrance and control point to the city. Its strategic geographic position, at the end of the road from Toledo, made it a landmark and provided the city with an important symbol (Fig. 5).

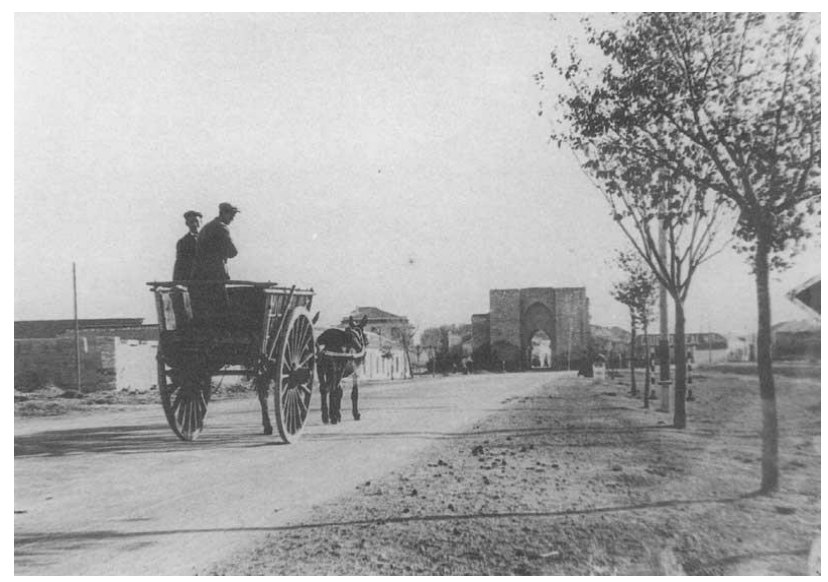

Figure 5. Historical view of the road from Toledo ending at the gate named accordingly. The right side of the enclosure had already disappeared

This has been a difficult task to accomplish as the only remains left were the gate itself, isolated and unacknowledged in the middle of a roundabout. It was interpreted more as a triumphal arch rather than as part of a defense enclosure for the city. There was no evidence in the surrounding urban environment that could help this purpose any longer as the context of the monument had already been completely altered.

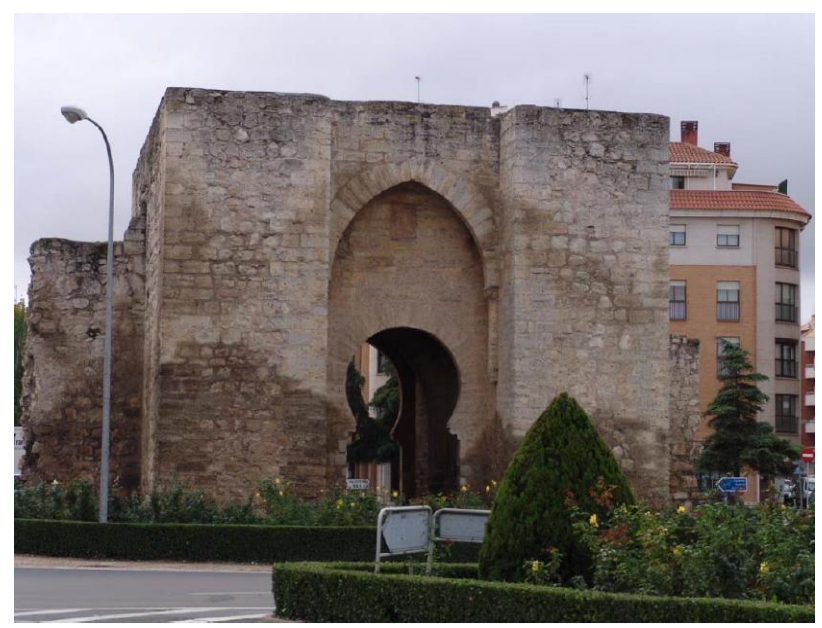

Figure 6. View of the Toledo Gate before the conservation works, with clear evidences of humidity problems coming from the ground and the terrace

Beside interpretation, the urban infrastructure also contributed to other important conservation challenges such as water drainage, high levels of airborne pollutants and stone deterioration. All of these were exacerbated by deferred maintenance and previous inappropriate conservation treatments such as the use of Portland cement mortar.

Together these issues defined the overall strategy for the conservation works (Fig. 6). Furthermore, there was the important intention to recover the gate as a public terrace where visitors could access and better understand the history of the city, the structure itself and its original function as an entry point.

To further these aims vehicular traffic was redirected thus reconnecting the gate to the city. It was no longer isolated in a roundabout. The gate was recovered as a pedestrian entry and connected to the Plaza de España, in the city centre. Low walls on both sides of the gate were reconstructed thus directing pedestrians through the gate. This reinforced the understanding of the gate as part of an enclosure with no other way to cross from outside to inside except through the gate itself.

Also, the restitution onsite of replicas of the wooden doors and the portcullis were extensively discussed but it was finally considered an unnecessary addition to the monument, as a 3D virtual model could show the complete configuration of its mechanisms in all their detail and functionality.

This additional interpretation and communication tool liberated the monument from a certain level of pressure coming from the need to recreate additional portions of the gate by adding features during the works. Adding features were desired in order to help increase the monumentality and presence of the gate in the city as a significant element. Yet, this risked losing the original form and context thus jeopardizing authenticity.

\subsection{The archaeological investigations}

The in-depth archaeological excavations and research were carried out and resulted in some key considerations that led to further decisions concerning the project. This included the already mentioned discovery of the foundation remains of a second enclosure of walls, adjacent to the gate, which origins were traced back to the times of Alfonso the $10^{\text {th }}$.

Also, ponds for ice production were discovered and identified in the adjacent area outside the lost walls at both sides of the gate. This industrial use of the immediate surroundings of the gate has been identified as one, but not the only, sources of humidity that have stained the stone throughout the past century. The rising dampness has caused a slow and chronical deterioration, from the physical and chemical point of view. Finally, the original pavement level of the entrance corridor with its original slope towards away from the gate was identified.

The initial discovery of interesting archaeological remains on the roof during the preliminary investigations led to the recommendation to preserve them under a protective wooden floor with an empty cavity in between to avoid accumulation of humidity. This floor would have had windows to permit visitors to observe specific archaeological features such as the vault key stones below and the traces of the guard rooms. However, as the investigations proceeded the reality turned out to be completely different. The research brought to light that the gate originally had a second floor and the volume therefore was almost double than how it appears nowadays (Fig. 7). At this stage of the 
process the virtual reconstruction models aided considerably in exploring and explaining possible construction hypothesis.

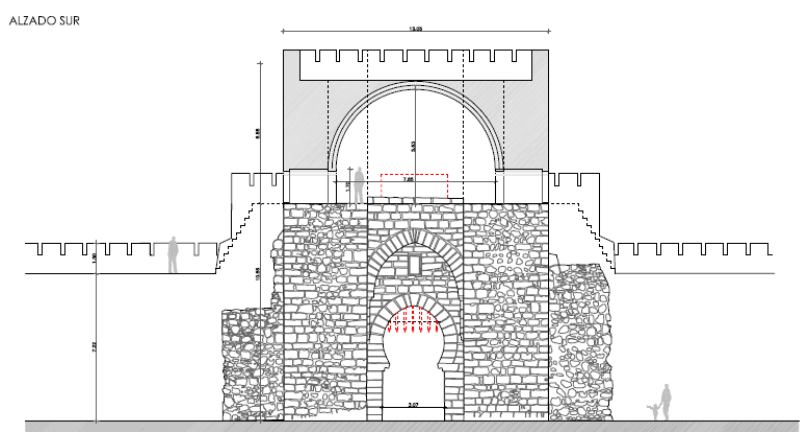

Figure 7. Hypothetical elevation of the gate with the second floor and the connection with the parapet walks on both sides

This important discovery turned upside down the previous hypothesis developed in the 1920s giving a completely new and unexplored interpretation of the gate. The previous idea, which was never completed due to lack of funding, suggested a gate with only one floor finished with crenellations on top (Ramírez, 2009).

Proportions and construction principles were studied through other surviving contemporary examples in the area, as well as the observation and study of the historic photographs. Photographs that, when studied collectively and in parallel with other data and if observed in detail, showed hidden features that corroborate this hypothesis. They were certainly awaiting identification and discovery.

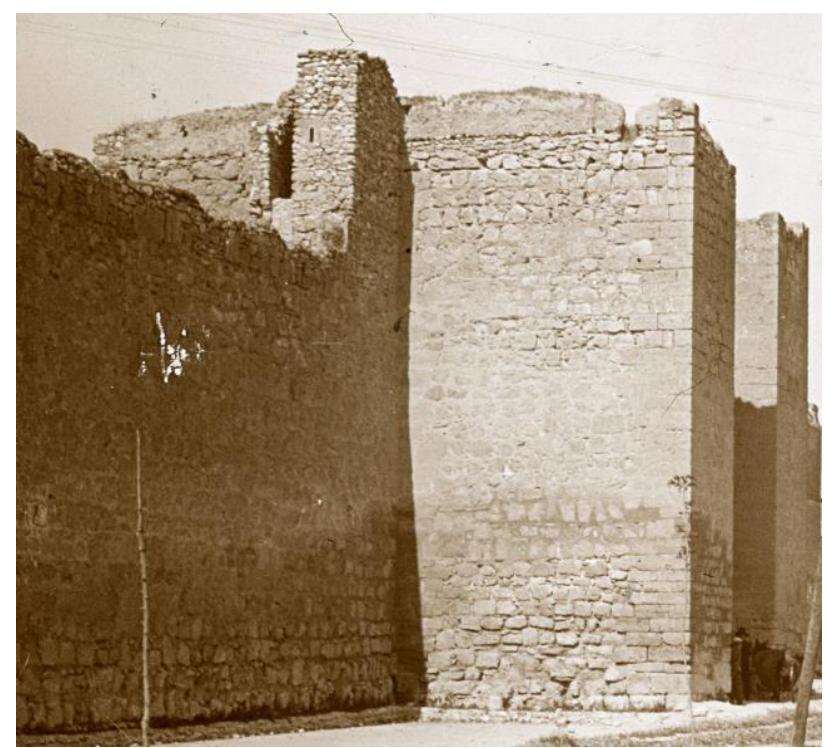

Figure 8. Historic photograph research permitted identification of a lost staircase that connected the upper ramparts of the walls

to the second floor of the gate. The images also revealed evidence of a rammed earth level that defined the second level

Examples of these hidden features include the case of the lost archer loopholes that still can be identified on the historic photos (Figs. 3 and 8), and the lost staircases that connected the upper ramparts of the walls and the second floor of the gate (Fig. 8). These and other examples (Fig. 9, 10 and 11), give credibility and support to additional aspects of the new reconstruction hypothesis that has solid foundations to be scientifically accepted.

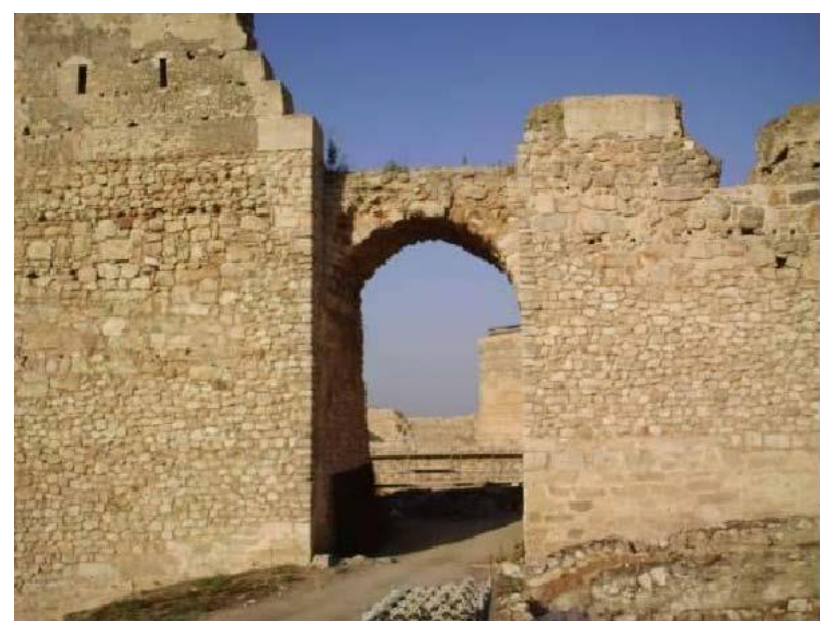

Figure 9. Access to the fortress of Calatrava la Vieja, near Ciudad Real. Still visible on top of the masonry is an additional section of the wall made in rammed earth and finished with crenellations

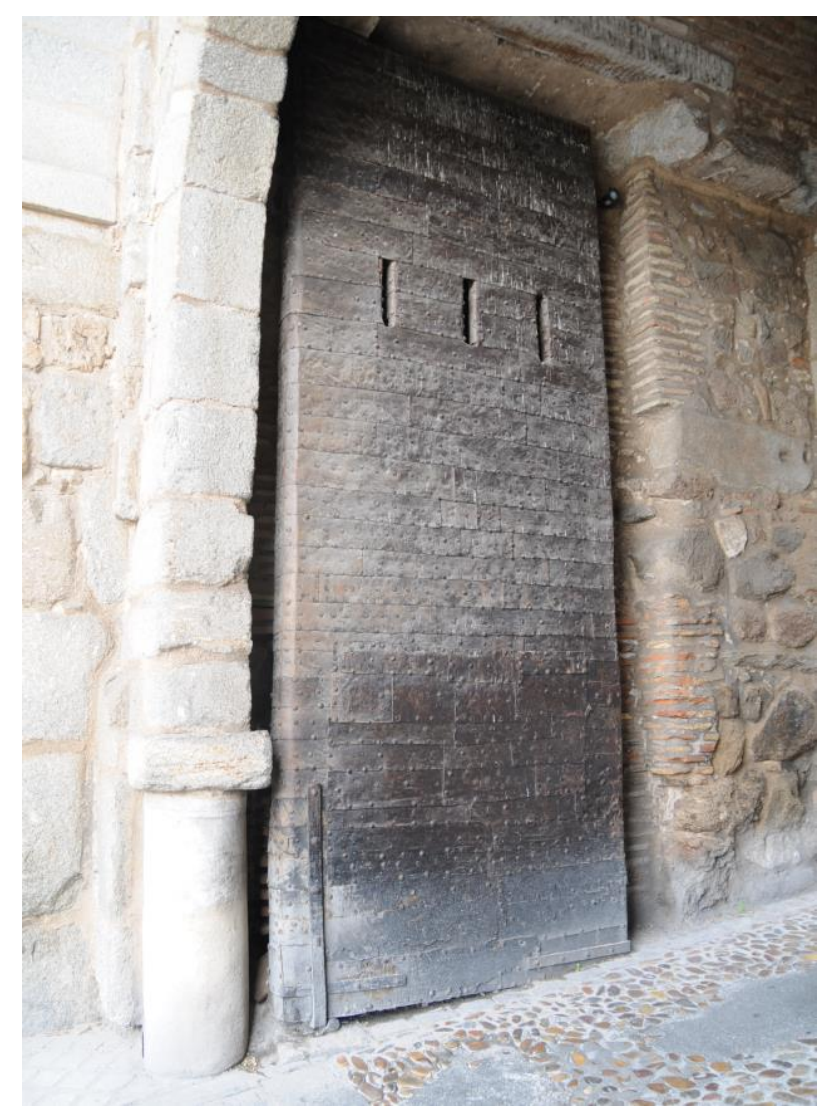

Figure 10. The curious case of a historic mediaeval portcullis reused as a door at the Cambrón Gate, in the walls enclosure of the city of Toledo 


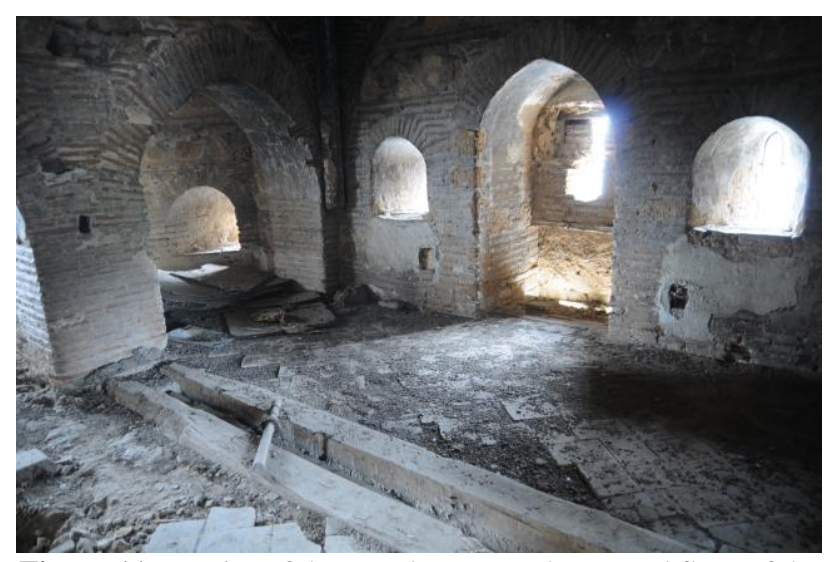

Figure 11. Interior of the guard room on the second floor of the Alcántara Bridge in Toledo that inspired and supports the reconstruction hypothesis of the Toledo Gate in Ciudad Real

This research has therefore permitted the definition of a gate reconstruction hypothesis from the Alfonsí period that is mainly characterized by a straight access through the gate with a double vaulted room, protected with vertical defence mechanisms (portcullis and machicolations). This leaves no doubt to the need of a second level of construction.

This particular construction typology can be identified not far away from Ciudad Real, in some of the works for the walls and bridges of the city of Toledo: the cases of the Alcántara Bridge, Valmardón Gate, Sol Gate, Bisagra Gate, as well as the entrance gate to Calatrava la Vieja (Fig. 9), in the province of Ciudad Real, and other villages and towns such as Badajoz, Burgos, Atienza and Almansa.

\section{THE 3D MODEL AS A RESEARCH TOOL}

\subsection{The impact of the 3D model in the investigation}

With such a discovery, in fact, the potential and impact of the virtual 3D model in this project has been extraordinary helpful. It allowed the team to balance the physical intervention on the monument itself with the virtual reconstruction to explain certain aspects that otherwise would have been considered too intrusive to implement.

In this sense the combination of the virtual and the real (Fig. 12) now permits a new, in-depth understanding of the gate in its original context. This goes beyond what the real monument shows and transmits to the observer some aspects which are impossible to highlight physically without a contradictory effect.

The digital reconstruction accomplishes perfectly this mission, helping to enhance these additional values without fear of losing authenticity and complimenting the real observation and understanding. Furthermore, it easily permits the identification of what is original and what is hypothetical (Seville Principles 2011).

The 3D model was originally introduced as a tool for communication purposes during the project in order to raise awareness about its importance and uniqueness. However following the project development it has become a much more powerful tool that was useful for testing, analyzing, studying and contrasting archaeological evidences and historical data.

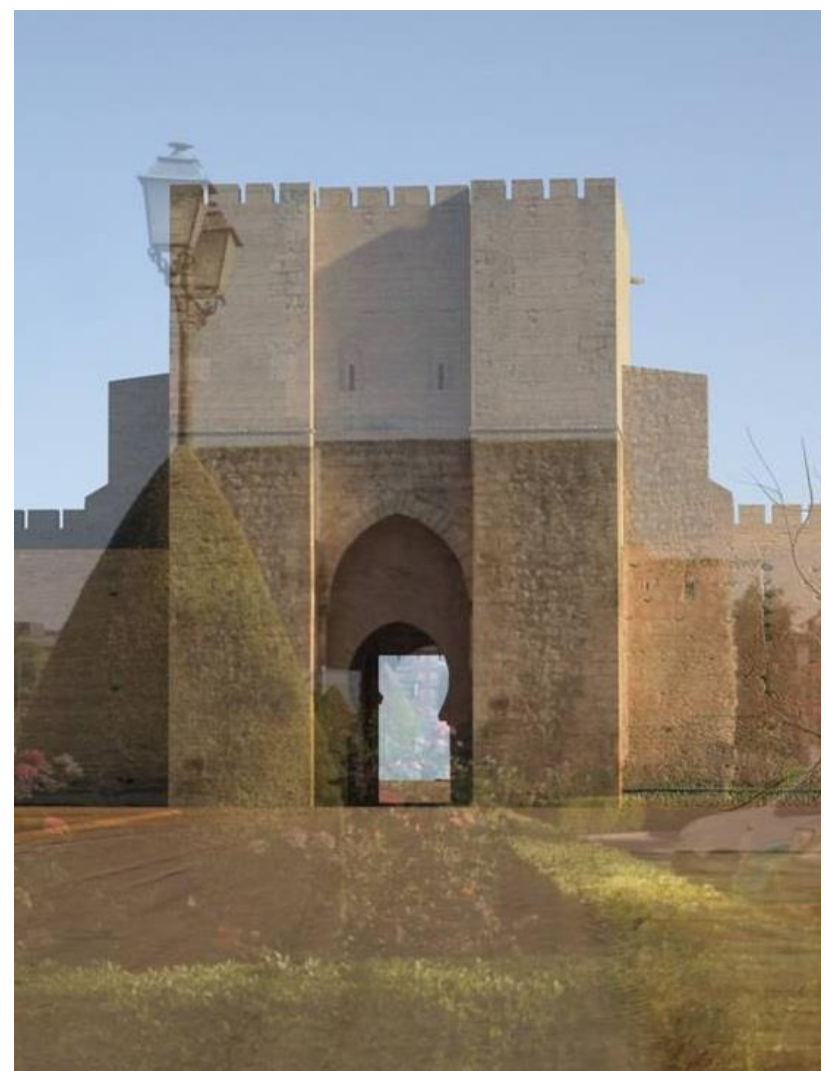

Figure 12. Photomontage of the Toledo Gate that merges the real and the virtual together

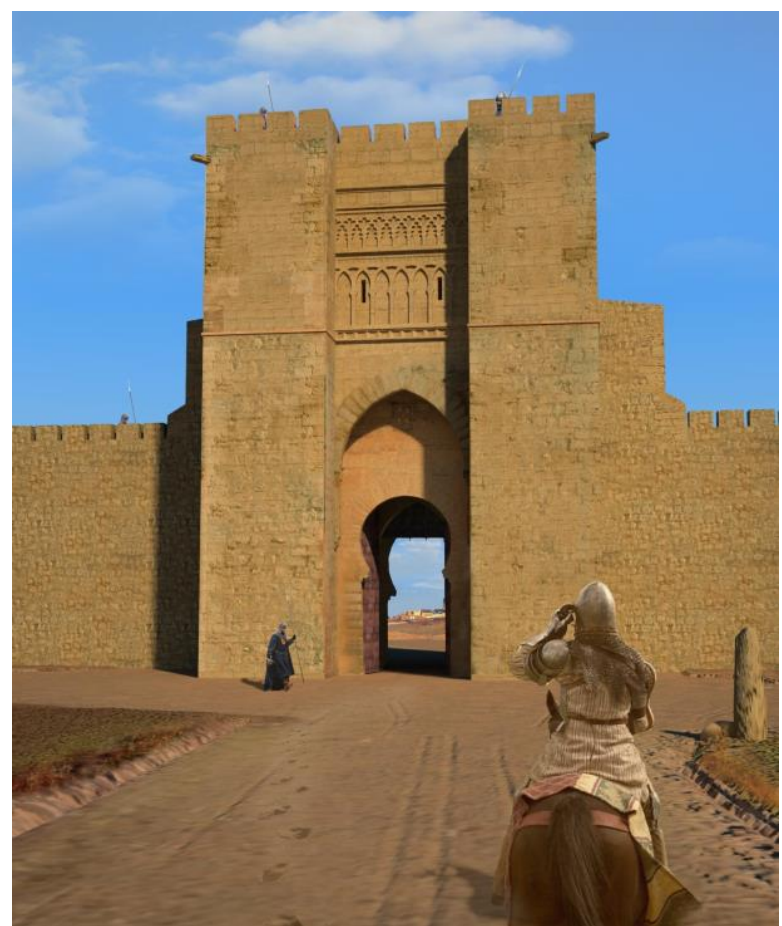

Figure 13. Monumental and imposing view of the gate from outside the walls 


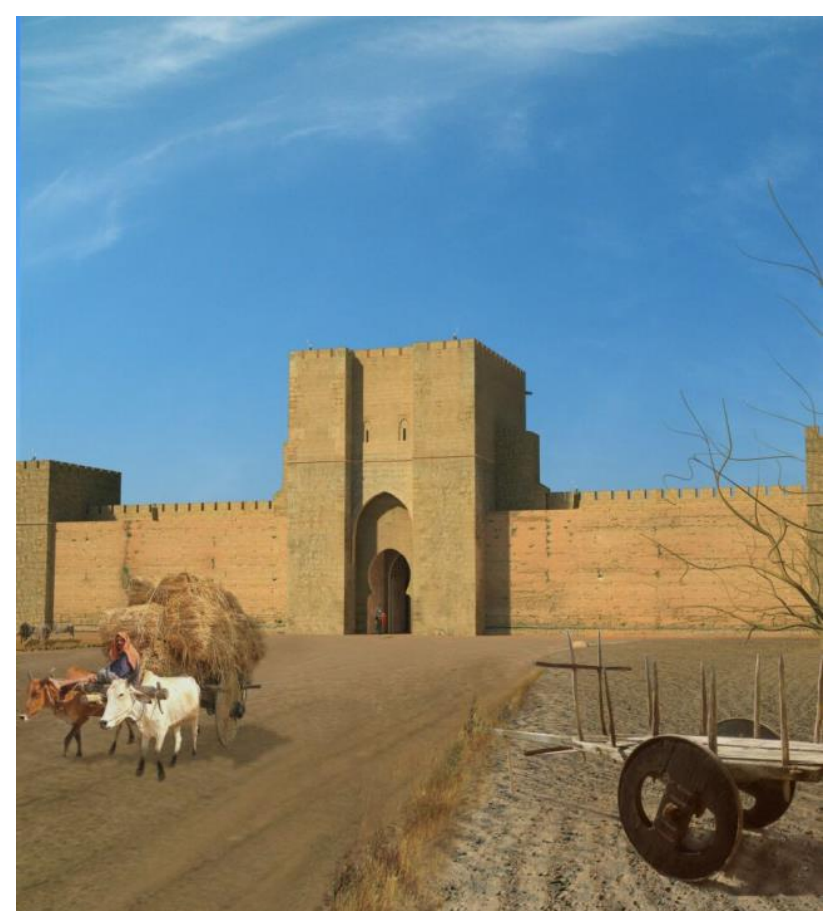

Figure 14. Reconstruction view of the gate and the walls from inside the enclosure

It permitted the merger of a new reconstruction hypothesis providing a new interpretation of the origins of the gate. In fact, the study of this hypothesis would have been extremely difficult without the digital tools, as the study of 3D features in elevation and plan has historically not permitted a full analysis of the complexity of construction solutions - the key to understanding how the gate was conceived and functioned in the past.

\subsection{A step forward in the interpretation of the gate}

The appearance of the second floor as a closed space in between sections of the walls and that contained the mechanisms to hoist the portcullis was not a complete surprise if other coetaneous examples are analysed in detail. As previously mentioned, other gates in the area still preserve the original mechanisms, such as the tower of the Alcántara Bridge (Fig. 11) or the Valmardón Gate in the city of Toledo. One of the difficulties that this reconstruction faced was the definition of the external and internal elevation of the second floor of the gate (Fig. 7). Some photographic evidences point out the existence of archer loopholes that match with contemporary examples that follow the same typology (Figs. 3, 8, 13 and 14).

In fact, the typology of this second floor is highly validated thanks to other examples as well as the need for the guard room. From this room upstairs it was possible to proceed with the defence of the gate through the machicolations, to control the hoist of the portcullis (Fig. 15) and to control the loopholes to defend the road that came from Toledo.

It also served to watch access to the lower and upper levels, and, above all, to give continuity to the upper rampart of the walls and the gate through covered walkways and staircases. These connected the level difference between the walls and this second floor. Most importantly, there is no doubt that the raised height of the second floor gave the entrance to Ciudad Real a more monumental and imposing appearance (Fig. 13).

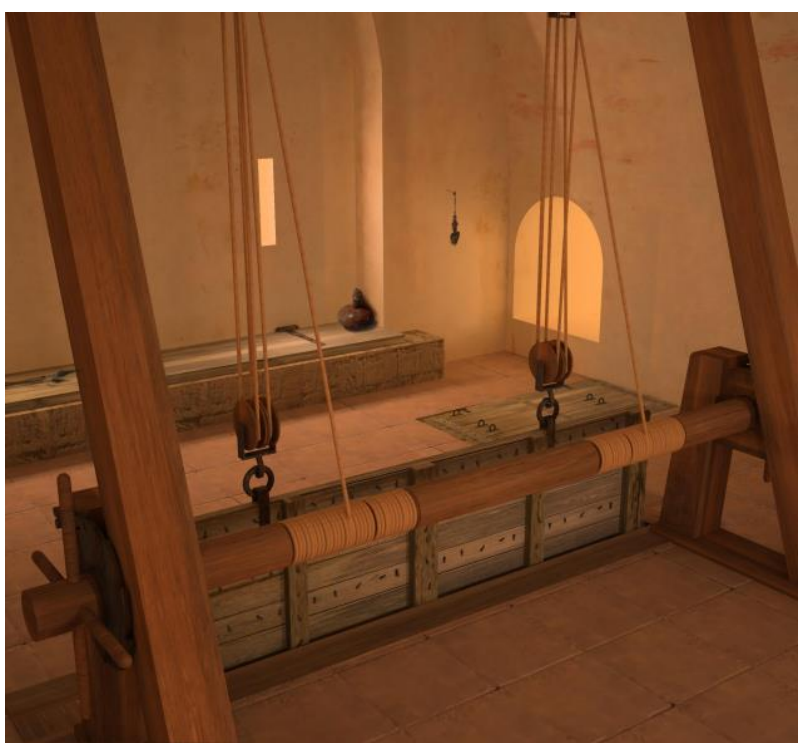

Figure 15. View of the portcullis mechanism that were installed on the second floor of the gate

\section{CONCLUSIONS}

The usefulness and potential of virtual 3D modelling in a research process and physical conservation intervention becomes extremely clear when developing a project such as the Toledo Gate of Ciudad Real. The opportunity to investigate and explore in 3D various options and theories of historic construction brings new perspectives to the interdisciplinary approach.

The development of the 3D model in parallel with the archaeological excavation and the historical research immediately before as well as during the conservation work permitted an interaction that is uncommon in this type of project. This resulted in a much more powerful outcome for both the virtual reconstruction and the physical conservation of the monument.

In this regard, the 3D modelling process has become a powerful decision making tool for crafting the final solution of the actual roof which was originally the second floor (Fig. 16). The final solution of the roof was constructed highlighting the original structural features of this upper floor, according to all the archaeological evidences and the contemporary examples under study (portcullis mechanism, loopholes, machicolations, access to rampart staircases and ground floor, etc.). This would not have occurred if the virtual model had not been conceived by a multidisciplinary team using all the evidence available and contributing to the proposed hypothesis.

In this sense it can be reaffirmed how important it becomes to visualize solutions that are too intrusive to be physically recreated. The $3 \mathrm{D}$ modelling process can inform conservation to intermediate solutions to balance the evident origins without a strong physical impact on the monument (Figs. 13, 14, 15 and 17).

The final virtual 3D model will be used to create permanent didactic displays and videos to aid in interpretation and awareness raising. It was featured on the website of the city, the 
Montemadrid Foundation as well as in newspapers alongside articles about the archaeological investigations and conservation project.

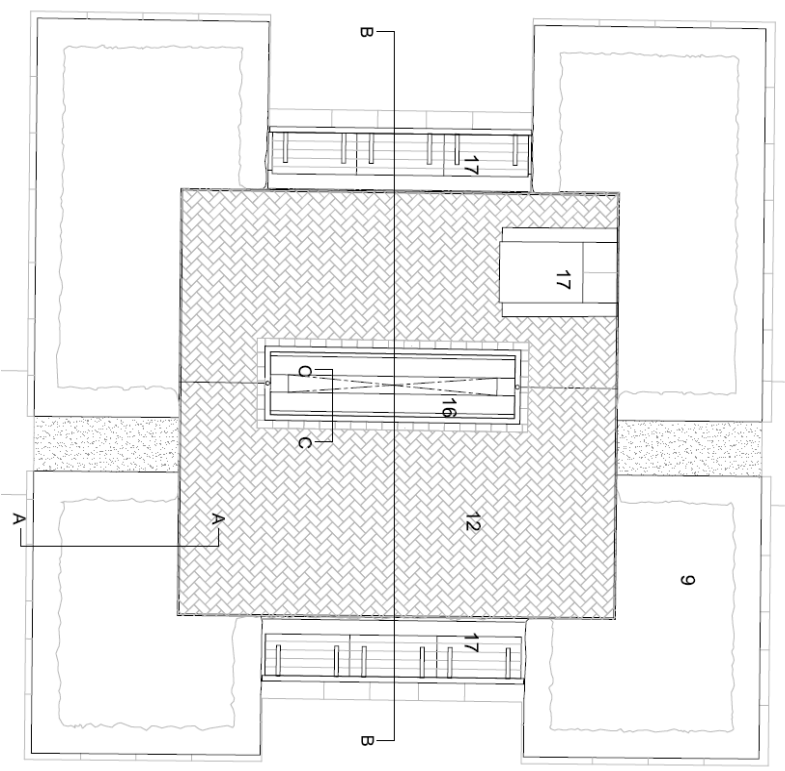

Figure 16. Final intervention plan on the actual roof terrace that incorporates the new interpretation of the second floor of the gate through the pavement and other finishes

There is now a special interest in the further development of an augmented reality platform in order to provide interactive onsite interpretation via smartphones. In this case, it is an appropriate tool for explaining and understanding the gate, its importance to Ciudad Real as well as its function and surroundings without extensive or intrusive physical recreations.

Once the main research was concluded and the hypothesis of the second floor scientifically accepted by the academic community the usefulness of the 3D model was clear.

In conclusion, 3D virtual models are not only for interpretation but are an essential tool during any conservation project. They must be developed from the beginning bringing together all historic evidence from investigations onsite and archives. Multiple iterations of model incorporate ideas as discoveries were made and discussed. Such models are platforms for the team to discuss final conservation interventions and weigh alternatives. They are useful not only in meetings with decision makers but also with the numerous stakeholders. Finally, such models are the link between the technical team, the public and their history - to raise awareness and enhance historic, architectural and scientific values.

In the case of the Toledo Gate of Ciudad Real it has improved the perceptions and increased appreciation of an important monument that was once an ignored element isolated in a roundabout. People are now able to visit the monument, enjoy the surrounding park, scale the gate and view the complex structure. They are learning of their own architectural history from the gate itself and the virtual 3D model.

The virtual has truly influenced reality.

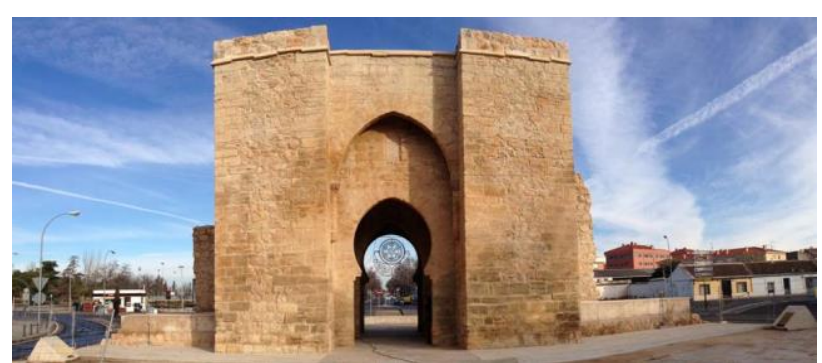

Figure 17. View of the Toledo Gate after the restoration works

\section{REFERENCES}

Almagro Vidal, A., Gómez Merino, J. L., Ramírez González, I., 2011. "The Toledo Gate in Ciudad Real, Spain. An applied case study of the Seville Charter" in Proceedings of the XXIII International Scientific Symposium of CIPA, Prague, 12-16 September 2011.

Golderos Vicario, J., 2004. La batalla de Ciudad Real (marzo 1809). Un episodio casi desconocido, Ciudad Real.

Ramírez González, I., 2010. Informe de excavación arqueológica en el área afectada por la restauración y rehabilitación de la Puerta de Toledo de Ciudad Real, Unpublished report. Fundación Montemadrid.

Villegas Díaz, L.R., 1981. Ciudad Real en la Edad Media. La ciudad y sus hombres (1255-1500), Ciudad Real, pp. 56-61.

Villegas, L. R., 1984. El urbanismo de Ciudad Real en la Edad Media (Datos y reflexiones), Ciudad Real, pp.33-34.

VV.AA., 1993. Historia de Ciudad Real. Espacio y tiempo de un núcleo urbano. Toledo.

VV.AA., 2011. Seville Principles, International Forum of Virtual Archaeology, Final Draft. 